\title{
Vague Seperation and Connectedness
}

\author{
V. Amarendra Babu, R. Ramya Swetha, T. Anitha
}

\begin{abstract}
In this paper we blessing dark standard space, questionable run of the mill space,vague entire common zone and besides deduce a couple of speculations on those. also mean cloud connectedness, dicey unequivocally connectedness, unsure insistently disconnectedness, questionable C5 detached, part and additionally choose a couple of theories.
\end{abstract}

Keywords: Vague regular space, Vague normal space, Vague connectedness, Vague strongly connectedness

\section{INTRODUCTION}

Zadeh provided the idea of fleecy units in 1965[12]. A vague Set is an also theory of a Fuzzy set. questionable set transformed into given by methods for Gau and Burherer and referenced the properties of uncertain units. instead of using point-based cooperation as in cushy sets, period in the middle of basically based enlistment is connected in an undefined set. The period in the middle of based investment in undefined set is more noteworthy expressivein getting uncertainty of records. The theory of cushy topology become made by means of C.L Chang[2] in 1967.primarily dependent on those thoughts C.L. Chang gave the soft topological space in 1968. He present cushy open set and fleecy close sets. those two foresee imperative action in soft topology. various makers provided a first rate arrangement of wears down cushy set and fleecy topological space.

by and by a days such enormous quantities of researchers developed their investigation on far fetched theory. T.Anitha and V.Amarendra Babu [9] evolved the theory of questionable LI-convictions in 2015 by utilizing connected the dark hypothesis and LI-perfect hypothesis of go area thought algebras.V.Amarendra babu and ok.V.Rama Rao[10,11]brought and developed the vague algebralike as uncertain presented substance social events and questionable topological get-togethers in 2017.

The speculation of hazy topology become introduced by Mariapresenti.L and Arockia Rani [5]. She developed the speculation of ill defined generlized alpha close sets in far fetched topological space and discussed thier properties.

In our past work we blessing some indispensable properties ofVague Topology and called attention to thier habitations. further we speak to darken minimization, vague segment adages and called attention to their homes.

on this paper we're offering obscure customary area,vague standard territory, unclear complete ordinary space, vague conncetedness, vague solidly connectedness, ill defined

Revised Manuscript Received on April 12, 2019.

V. Amarendra Babu, Department of Mathematics, Acharya Nagarjuna University, Nagarjuna Nagar, A.P, India (E-mail: amarendravelisela@ymail.com)

R. Ramya Swetha, Department of Mathematics, Gandhiji Institute of Science and Technology, Jaggayyapet, A.P, India (E-mail: ramya.swetha19@gmail.com)

T. Anitha, Department of Mathematics, KL University, Vaddeswaram, Guntur, A.P, India. (E-mail: anitha.t537@gmail.com) decidedly disconnectedness and tried their living arrangements.

\section{PRELIMINARIES}

Definition 2.1[4]: A dubious set P known to man of talk L is portrayed by two participation capacities given by, a genuine enrollment work $t_{P}: \mathrm{L} \rightarrow[0,1]$ and a false membership function $f_{P}: \mathrm{L} \rightarrow[0,1]$. The grade of membership of $\mathrm{y}$ in the vague set $\mathrm{P}$ is bounded by a sub interval $\left[\boldsymbol{t}_{P}(y),{ }^{1-f_{P}(y)}\right]$ of $[0,1]$. This indicates that ,if the actual grade of membership $\mu(x)$, then $t_{P}(y) \leq \mu(y) \leq 1-f_{P}(y)$. The vague set $\mathrm{P}$ is written as $P=\left\{y,\left[t_{P}(y), 1-f_{P}(y)\right] / y \in X\right\} \quad, \quad$ where the interval $\left[t_{P}(y), 1-f_{P}(y)\right]$ is called the vague value of $\mathrm{y}$ in $\mathrm{P}$ and is denoted by $\mathrm{V}_{\mathrm{P}}(\mathrm{y})$.

The zero vague set of $\mathrm{P}$ and denoted by $\mathbf{0}$ and defined as $\mathbf{0}$ $=\{\langle x,[0,0]\rangle / x \in P\}$.

The unit vague set of $\mathrm{P}$ and denoted by $\mathbf{1}$ and defined as $\mathbf{1 =}$ $\{\langle\mathrm{x},[1,1]\rangle / \mathrm{x} \in \mathrm{P}\}$

Definition 2.2[1]: An ambiguous topologyon $P$ is a family $\sigma$ of unclear sets on $\mathrm{P}$ fulfilling the accompanying conditions:0, $1 \in \sigma$

1. $\mathrm{A}_{1} \cap \mathrm{A}_{2}$, for any $\mathrm{A}_{1}, \mathrm{~A}_{2} \in \sigma$.

2. $\cup A_{i} \in \sigma$, for any arbitrary family $\left\{A_{i} / A_{i} \in \sigma, i \in I\right\}$.

The pair $(P, \sigma)$ is called a vague topological space. The elements of $\sigma$ are called vague open sets.

Definition 2.3[7 ] : A vague topological space $(\mathrm{P}, \sigma)$ is calledVT $\mathrm{V}_{1}$ space if all pair of distinct vague points $p_{a}^{(\alpha, \beta)}$, $p_{b}^{(\gamma, \delta)}$ of $\mathrm{X}$ there exist $\mathrm{U}, \mathrm{V} \in \tau$ suchthat

$$
p_{a}^{(\alpha, \beta)} \in \mathrm{U}, p_{a}^{(\alpha, \beta)} \notin \mathrm{V} \text { and } p_{b}^{(\gamma, \delta)} \in \mathrm{V}, p_{b}^{(\gamma, \delta)} \notin \mathrm{U} \text {. }
$$

Definition 2.4[7] : A vague topological space $(\mathrm{P}, \sigma)$ is called $\mathrm{VT}_{2}$ space or Vague Haussdorff space if for all pair of distinct vague points $p_{a}^{(\alpha, \beta)}, p_{b}^{(\gamma, \delta)}$ of $\mathrm{X}$ there exist $\mathrm{U}, \mathrm{V} \in \tau$ suchthat $\mathrm{U} \cap V=\varnothing$ and $p_{a}^{(\alpha, \beta)} \in \mathrm{U}, p_{b}^{(\gamma, \delta)} \in \mathrm{V}$.

Definition 2.5[ 6 ] : An associated area is a topological space $\mathrm{X}$ which cannot be spoken to because the affiliation of two disjoint non-void open units.If the topological space isn't related is referred to as indifferent. 
Definition 2.6[ 6 ] : A completely disengaged space is a topological space $\mathrm{X}$ where each pair of particular focuses can be isolated by a detachment of $\mathrm{X}$.

Definition 2.7 [ 7] :Let $(\mathrm{X}, \tau),(\mathrm{y}, \sigma)$ are two vague topological spaces. Then a mapping $\mathrm{f:}(\mathrm{X}, \tau) \rightarrow(\mathrm{y}, \sigma)$ is called a vague $\alpha$ generalised open mapping if $\mathrm{f}(\mathrm{A})$ is a vague $\alpha$ generalised open set in $\mathrm{Y}$ for each vague open set $\mathrm{A}$ in $\mathrm{X}^{\prime}$.

\section{VAGUE REGULAR SPACES AND NORMAL SPACES}

In this stage we plot ill defined ordinary territory, unclear typical space,vague complete normal region and moreover determine a few hypotheses on those

Definition 3.1 : If $\mathrm{A}$ is a vague closed set of a vague topological space $(\mathrm{X}, \tau)$ and $\mathrm{x}$ is any point in $\mathrm{X}$ such that $\mathrm{x}$ does not belongs to $A$, there exist open sets $U_{A}$ and $U_{x} \in \tau$ containing $\mathrm{A}$ and $\mathrm{x}$ respectively. Then $(\mathrm{x}, \tau)$ is called vague regular space.

Definition 3.2 : If A and B are disjoint vague closed sets in a vague topological space $(X, \tau)$ there exist vague open sets $\mathrm{U}_{\mathrm{A}}$ and $\mathrm{U}_{\mathrm{B}} \in \tau$ containing $\mathrm{A}$ and $\mathrm{B}$ respectively. Then $(\mathrm{X}, \tau)$ is called vague normal space.

Definition 3.3 : If A and B are vague separated sets in a vague topological space $(X, \tau)$ there exist vague open sets $U_{A}$ and $\mathrm{U}_{\mathrm{B}} \in \tau$ containing $\mathrm{A}$ and $\mathrm{B}$ respectively. Then $(\mathrm{X}, \tau)$ is called vague completely normal space.

Proposition3.4:Every sub space of a vague regular space is regular.

Proof : Let A be subspace of a vague regular space X.

Now we have to show that $\mathrm{A}$ is a vague regular space of $\mathrm{X}$.

Let $\mathrm{P}$ is a point in $\mathrm{A}$ implies $\mathrm{p} \in \mathrm{X}$. Since $\mathrm{X}$ is regular space ,F is a vague closed of $\tau / A \subseteq \tau$ and

a $\notin F$ there exist vague open sets $U_{F}$ and $U_{a} \in \tau / A$ containing $\mathrm{F}$ and a respectively.

Therefore $\mathrm{A}$ is vague regular.

Proposition 3.5 : If every point $\mathrm{p}_{\mathrm{x}}{ }^{(\alpha, \beta)}$ of a vague topological space $X$ has a vague closed neighbourhood which is a regular space of $X$ then $X$ is vague regular.

Proof : Let $(X, \tau)$ be a vague topological space. Now show that $\mathrm{X}$ is a vague regular space.

Let $F$ be a vague closed set and $p_{x}{ }^{(\alpha, \beta)}$ is a point in $X$ this vague point $\mathrm{p}_{\mathrm{x}}{ }^{(\alpha, \beta)}$ has a vague closed $\mathrm{X}$.

neighbourhood $F_{x}, p_{x}^{(\alpha, \beta)} \notin F$, which is a regular space of

There exist vague open sets $U_{F}$ and $U x$ containing $F$ and $x$ respectively such that $\mathrm{p}_{\mathrm{x}}{ }^{(\alpha, \beta)} \in \mathrm{F}$ then there exist vague open sets $U_{F}$ and $U_{x}$ containing $F$ and $x$ respectively.

Remark 3.6 : Every vague completely normal space is a vague normal space .

Remark 3.7 : Every vague normal space is a vague regular space.

Corollory 3.8 : deliver $\mathrm{f}$ and $\mathrm{g}$ a hazard to be two ceaseless mappings of a topological space $\mathrm{X}$ into a haussdorff space $\mathrm{Y}$ then the association of all $x \in X$ with the give up intention that $f(x)=g(x)$ is close in $X$.

Verification : permit $f$ and $g$ be two steady mappings of a topological area X right into a haussdorff area Y.

give $\mathrm{x}$ and $\mathrm{y}$ a chance to be two points in $\mathrm{X}$ with the cease purpose that $f(x)=g(x), f(y)=g(y)$ wherein $f(x), f(y)$ are additives in $\mathrm{Y}$. due to the fact $\mathrm{Y}$ is a haussdorff area there exist obscure open units Ux and Uy with the give up purpose that $f(x) \in U x$ and $f(y) \in U y$ and $U x \cap U y=0$.

\section{VAGUE CONNECTED SPACES}

on this place wedefine uncertain connectedness, ambiguous emphatically connectedness, doubtful unequivocally disconnectedness, obscure C5 separated, part and moreover infer a few hypotheses.

Definition four.1: A dubious topological area $(\mathrm{X}, \mathrm{T})$ is said to be uncertain separated if there exist non- 0 ambiguous open sets $A n$ and $B$ in $X$ with the give up purpose that $\mathrm{a} U B=1$ and $\mathrm{A} \cap \mathrm{B}=$ zero .If $\mathrm{X}$ is not difficult to understand disengaged then it's far said to be ambiguous related.

Example 4.2 : Let $X=\{a, b\}, \tau=\{0,1, A, B\}$ where $\mathrm{A}=\{\langle\mathrm{a}[0.3,0.6]\rangle,\langle\mathrm{b}[0.4,0.7]\rangle\}$,

$\mathrm{B}=\{\langle\mathrm{a}[0.4,0.7]\rangle,\langle\mathrm{b}[0.4,0.8]\rangle\}$.

$\mathrm{AU} B=\{<a[0.4,0.7]\rangle,<b[0.4,0.8]\rangle\} \neq \mathbf{1}$

$A \cap B=\{<a[0.3,0.6]>,<b[0.4,0.7]>\} \neq \mathbf{0}$

Hence $\mathrm{X}$ is connected.

Proposition 4.3 : Let $\mathrm{f}:(\mathrm{X}, \tau) \rightarrow(Y, \sigma)$ be a vague irresolute surjection, $(\mathrm{X}, \tau)$ is vague connected then $(Y, \sigma)$ is vague connected.

Proof:Assume that $(\mathrm{Y}, \sigma)$ is not vague connected then there exist non-empty vague open sets $\mathrm{A}$ and $\mathrm{B}$ in $\mathrm{Y}$ such that $\mathrm{A} \cup B=\mathbf{1}$ and $\mathrm{A} \cap B=\mathbf{0}$, since $\mathrm{f}$ is vague irresolute map,

$\mathrm{C}=\mathrm{f}^{-1}(\mathrm{~A}) \neq \mathbf{0}, D=\mathrm{f}^{-1}(\mathrm{~B}) \neq \mathbf{0}$ which are vague opensets in $\mathrm{X}$

$\mathrm{f}^{-1}(\mathrm{~A}) \cup \mathrm{f}^{-1}(\mathrm{~B})=\mathrm{f}^{-1}(\mathrm{~A} \cup \mathrm{B})=\mathrm{f}^{-1}(1)=1$ which implies $\mathrm{C} \cup$ $D=\mathbf{0}$.

Thus $\mathrm{X}$ is vague disconnected, which is a contradiction to the hypothesis, hence $\mathrm{Y}$ is vague connected.

Definition4.4 : A vague topological space $(X, \tau)$ is vague strongly connected if there exist no non empty vague closed sets $\mathrm{A}$ and $\mathrm{B}$ such that $\mu_{\mathrm{A}}+\mu_{\mathrm{B}} \supseteq \mathbf{1}$ and $\left(1-v_{\mathrm{A}}\right)+\left(1-v_{\mathrm{B}}\right) \supseteq \mathbf{1}$.

In another words

A vague topological space $(\mathrm{X}, \tau)$ is vague strongly connected if there exist no non-empty vague closed sets $A$ and $\mathrm{B}$ in $\mathrm{X}$ suchthat $\mathrm{A} \cap \mathrm{B}=\mathbf{0}$

Example 4.5 : Let $\mathrm{X}=\{\mathrm{a}, \mathrm{b}\}, \tau=\{0,1, A, B\}$ where $\mathrm{A}=\{\langle\mathrm{a}[0.5,0.5]\rangle,\langle\mathrm{b}[0.5,0.5]\rangle\}$,

$\mathrm{B}=\{\langle\mathrm{a}[0.6,0.8]\rangle,\langle\mathrm{b}[0.5,0.6]\rangle\}$.

Here $A \cap B=A \neq 0$

Hence $\mathrm{X}$ is vague strongly connected.

Theorem 4.6 :Let $\mathrm{h}:(\mathrm{X}, \tau) \rightarrow(Y, \sigma)$ be a vague irresolute surjection, $(\mathrm{X}, \tau)$ is vague strongly connected then $(Y, \sigma)$ is also vague strongly connected.

Proof : Suppose that $\mathrm{Y}$ is not vague strongly connected then there exist vague closed sets $F_{1}$ and $F_{2}$ in $Y$ suchthat $\mathrm{F}_{1} \neq \mathbf{0}$,

$\mathrm{F}_{2} \neq \mathbf{0}, \mathrm{F}_{1} \cap \mathrm{F}_{2}=\mathbf{0}$. Since $\mathrm{h}$ is vague irresolute surjection

$\mathrm{h}^{-1}\left(\mathrm{~F}_{1}\right) \cap \mathrm{h}^{-1}\left(\mathrm{~F}_{2}\right)=\mathbf{0}, \mathrm{h}^{-1}\left(\mathrm{~F}_{1}\right) \neq \mathbf{0}, \mathrm{h}^{-1}\left(\mathrm{~F}_{2}\right) \neq \mathbf{0}$.

Hence $\mathrm{X}$ is vague strongly disconnected, which is a contradiction to our hypothesis.

So our assumption is wrong .

So $\mathrm{Y}$ is vague strongly connected. 
Theorem 4.7 : Let $Y$ be a vague topological space .If $\left\{\mathrm{K}_{\mathrm{i}}\right\}$ is a nonempty class of vague connected subspaces of $\mathrm{Y}$ suchthat $\cap K_{\mathrm{i}}$ is nonempty then $\mathrm{K}=\cup K_{\mathrm{i}}$ is also a vague connected subspace of $\mathrm{Y}$.

Proof :In a contrary way suppose that $\mathrm{K}$ is vague disconnected subspace of $\mathrm{Y}$.

So there exist two vague open sets $\mathrm{G}$ and $\mathrm{H}$ suchthat $\mathrm{GUH}$ $=\mathbf{1}$ and $\mathrm{G} \cap \mathrm{H}=\mathbf{0}$.

So ,that union GUH contains $\mathrm{K}$ and whose intersection with $\mathrm{K}$ are disjoint and non empty.

Since all the $\mathrm{K}_{\mathrm{i}}$ 's are connectedand each lies in GUH.

So each lies either in $\mathrm{G}$ or $\mathrm{H}$ and is disjoint from the other.

Since $\cap \mathrm{K}_{\mathrm{i}}$ is non empty , so all the $\mathrm{k}_{\mathrm{i}}$ 's completely in $\mathrm{G}$ and are disjoint from $\mathrm{H}$ or all completely in $\mathrm{H}$ and are disjoint from $\mathrm{G}$, which is a contradiction .

So our assumption is wrong.

So $\mathrm{K}=\cup K_{\mathrm{i}}$ is a vague connected subspace of $\mathrm{Y}$.

Theorem 4.8 : A topological space $(Y, \tau)$ is disconnected iff there exist a continuous mapping of $\mathrm{Y}$ onto the vague indiscrete space $\{\mathbf{0 , 1}\}$.

Proof : If $\mathrm{Y}$ is disconnected ,so there exist two vague open sets $\mathrm{G}$ and $\mathrm{H}$ such that

\section{$\mathrm{GUH}=\mathbf{1}, \mathrm{G} \cap \mathrm{H}=\mathbf{0}$.}

Now we define a mapping $\mathrm{f}$ from $\mathrm{X} \rightarrow\{\mathbf{0 , 1}\}$ as

If $\mathrm{p}_{\mathrm{x}}{ }^{(\alpha, \beta)}$ is a vague point of $\mathrm{X}$ then this point is belongs $\mathrm{G}$ or $\mathrm{H}$.

If this vague point is belongs to the vague open set $\mathrm{G}$ then we define $\mathrm{f}\left(\mathrm{p}_{\mathrm{x}}^{(\alpha, \beta)}\right)=\mathbf{1}$, if this vague point is belongs to the vague open set $H$ then we define $f\left(p_{x}{ }^{(\alpha, \beta)}\right)=\mathbf{0}$.

So $\mathrm{f}$ is vague continuous and onto mapping.

On the other hand if we have a vague continuous onto mapping f: $\mathrm{X} \rightarrow\{\mathbf{0 , 1}\}$.

Now we have to show that $\mathrm{X}$ is vague disconnected.

In a contrary way assume that $\mathrm{X}$ is vague connected.

We have a statement continuous image of a vague connected space is vague connected.

So if $X$ is vague connected then $\{\mathbf{0 , 1}\}$ is vague connected,but this is disconnected.

So our assumption is wrong.

So $\mathrm{X}$ is vague connected.

Definition 4.9 : A vague topological space $(X, \tau)$ is vague clopen disconnected if there exist vague set $\mathrm{A}$ in $\mathrm{X}$ which is both vague open set and vague closed set such that $A \neq 0$ and $A \neq \mathbf{1}$. If $X$ is not vague clopen disconnected then it is called vague clopen connected.

Example 4.10 : Let $\mathrm{X}=\{\mathrm{a}, \mathrm{b}\}, \tau=\{0,1, \mathrm{~A}\}$ where $\mathrm{A}$ $=\{\langle\mathrm{a}[0.5,0.5]\rangle,\langle\mathrm{b}[0.5,0.5]\rangle\}$.

Since $\mathrm{A}$ is both vague closed and vague open set then $\mathrm{X}$ is vague clopen disconnected space

Example 4.11: Let $X=\{a, b\}, \tau=\{0,1, A\}$ where $A$ $=\{\langle\mathrm{a}[0.3,0.6]\rangle,\langle\mathrm{b}[0.4,0.5]\rangle\}$

Since $\mathrm{A}$ is not both vague closed and vague open set then $\mathrm{X}$ is vague clopen connected space .

Theorem 4.12 :If $X$ is vague clopen connected space then $\mathrm{X}$ is vague connected space.

Proof: In a contrary way suppose that $\mathrm{X}$ is vague disconnected space.

So there exist non empty vague open sets $\mathrm{G}$ and $\mathrm{H}$ such that $\mathrm{G} \cup H=\mathbf{1}$ and $\mathrm{G} \cap \mathrm{H}=\mathbf{0}$

then $t_{A} \vee t_{B}=\mathbf{1},\left(1-f_{A}\right) \vee\left(1-f_{B}\right)=\mathbf{1}$ and then $t_{A} \wedge t_{B}$
$=\mathbf{0},\left(1-\mathrm{f}_{\mathrm{A}}\right) \wedge\left(1-\mathrm{f}_{\mathrm{B}}\right)=0$ and since $\mathrm{X}$ is vague clopen set .

So $\mathrm{G}$ and $\mathrm{H}$ are vague closed sets also,then again we have $\mathrm{G}^{\mathrm{C}} \cap \mathrm{H}^{\mathrm{C}}=\mathbf{0}$ and $\mathrm{G}^{\mathrm{C}} \cup \mathrm{H}^{\mathrm{C}}=\mathbf{1}$.

This implies $\mathrm{X}$ is vague disconnected space.

This is a contradiction to our hypothesis.

So $\mathrm{X}$ is vague connected space.

That is if $\mathrm{X}$ is vague clopen connected space then $\mathrm{X}$ is a vague connected space.

But the converse need not be true as shown in the following example

Example 4.13 : Let $X=\{a, b\}, \tau=\{0,1, A, B\}$ where

$\mathrm{A}=\{\langle\mathrm{a}[0.5,0.5]\rangle,\langle\mathrm{b}[0.5,0.5]\rangle\}$

and

$\mathrm{B}=\{\langle\mathrm{a}[0.5,0.7]\rangle,\langle\mathrm{b}[0.6,0.7]\rangle\}$

Clearly $\mathrm{A} \cup \mathrm{B}=\mathrm{B} \neq \mathbf{1}$ and $\mathrm{A} \cap \mathrm{B}=\mathrm{A} \neq \mathbf{0}$.

So $\mathrm{X}$ is vague connected .

Hence $\mathrm{X}$ is vague clopen disconnected.

Lemma4.14 : uncertain firmly associated does now not infer ambiguous clopen set and doubtful clopen related doesnot advocate difficult to understand emphatically related.

Example 4.15 : If $X=\{a, b\}, \tau=\{0,1, A, B\}$ where

$\mathrm{A}=\{\langle\mathrm{a}[0.5,0.5]\rangle,\langle\mathrm{b}[0.5,0.5]\rangle\}$

and

$\mathrm{B}=\{\langle\mathrm{a}[0.2,0.5]\rangle,\langle\mathrm{b}[0.3,0.5]\rangle\}$.

Here $A$ and $B$ are vague open sets in $X$ and $t_{A}+t_{B} \leq$ $\mathbf{1},\left(1-\mathrm{f}_{\mathrm{A}}\right)+\left(1-\mathrm{f}_{\mathrm{B}}\right) \leq \mathbf{1}$.

Hence $\mathrm{X}$ is vague strongly connected and vague clopen disconnected .

\section{RESULTS \& DISCUSSIONS}

Example 4.16 : Let $\mathrm{X}=\{\mathrm{a}, \mathrm{b}\}, \tau=\{0,1, \mathrm{~A}, \mathrm{~B}, \mathrm{~A} \cup \mathrm{B}, \mathrm{A} \cap \mathrm{B}\}$ where

$\mathrm{A}=\{\langle\mathrm{a}[0.3,0.7]\rangle,\langle\mathrm{b}[0.4,0.6]\rangle\}$ and

$\mathrm{B}=\{\langle\mathrm{a}[0.4,0.7]\rangle,\langle\mathrm{b}[0.5,0.6]\rangle\}$.

Here $\mathrm{X}$ is vague clopen connected because there is no vague clopen set .

But $\mathrm{t}_{\mathrm{A}}+\mathrm{t}_{\mathrm{B}} \leq \mathbf{1},\left(1-\mathrm{f}_{\mathrm{A}}\right)+\left(1-\mathrm{f}_{\mathrm{B}}\right) \geq \mathbf{1}$.

So $\mathrm{X}$ is not vague strongly connected.

Definition 4.17 : An ill defined completely disengaged region is an indistinguishable topological region $\mathrm{X}$ wherein each pair of great vague variables can be isolated by method for a separation of $\mathrm{X}$.

That means for every pair of distinct vague points $\mathrm{p}_{\mathrm{x}}{ }^{(\alpha, \beta)}$ and $\mathrm{p}_{\mathrm{y}}(\gamma, \delta)$ in $\mathrm{X}$ such that $\mathrm{x} \neq \mathrm{y}$ there exist a disconnection $\mathrm{X}=\mathrm{A} \cup B$ with $\mathrm{x} \in A$ and $\mathrm{y} \in \mathrm{B}$.

Definition 4.18: An ambiguous associated space which isn't appropriately contained in any bigger associated space is called dubious part of obscure associated space.

Theorem4.19: The components of a vague totally disconnected space are its vague points.

Proof: Let $\mathrm{X}$ be a vague totally disconnected space .

That is for every pair of distinct vague points can be separated by a disconnection of $\mathrm{X}$.

This means $\mathrm{X}=\mathrm{AUB}$ with $\mathrm{x} \in A$ and $\mathrm{y} \in \mathrm{B}$.

Now ,we have to show that every subspace $Y$ of $X$ which contains more than point is disconnected.

Let $\mathrm{p}_{\mathrm{x}}^{(\alpha, \beta)}$ and $\mathrm{p}_{\mathrm{y}}{ }^{(} \gamma, \delta^{)}$be distinct vague points in $\mathrm{Y}$ and let $\mathrm{X}=\mathrm{AUB}$ is adisconnection of $\mathrm{X}$ with $\mathrm{p}_{\mathrm{x}}{ }^{(\alpha, \beta)} \in \mathrm{A}$ and $\mathrm{p}_{\mathrm{y}}\left(\gamma, \delta^{)} \in \mathrm{B}\right.$. 
$\mathrm{Y}=(\mathrm{Y} \cap A) \cup(Y \cap B)$, since $\mathrm{A} \cap B=\emptyset$ that implies $(\mathrm{Y} \cap A) \cap(Y \cap B)=\varnothing$.

So $\mathrm{Y}$ is vague disconnected space.

Which is a contradiction.

So there is only one vague point in $\mathrm{Y}$.

Theorem4.20 : Let $X$ be a vague haussdorff space. If $X$ has a vague open base whose sets are also vague closed then $\mathrm{X}$ is vague totally disconnected space.

Proof: Let $X$ be a vague haussdorff space .Let $\mathrm{p}_{\mathrm{x}}{ }^{(\alpha, \beta)}$ and $\mathrm{p}_{\mathrm{y}}{ }^{(} \gamma, \delta^{\prime}$ be distinct vague points in $\mathrm{X}$.

That is there exist avague open set $\mathrm{G}$ which contains $\mathrm{p}_{\mathrm{x}}{ }^{(\alpha, \beta)}$ which does not contain $\mathrm{p}_{\mathrm{y}}(\gamma, \delta)$

By our assumption there exist a basic open set B which is also vague closed suchthat

$\mathrm{p}_{\mathrm{x}}^{(\alpha, \beta)} \in \mathrm{B} \subseteq G$.

So $\mathrm{X}=\mathrm{B} \cup B^{1}$ is clearly adisconnection of $\mathrm{X}$ which seperates $\mathrm{p}_{\mathrm{x}}{ }^{(\alpha, \beta)}$ and $\left.\mathrm{p}_{\mathrm{y}}{ }^{(} \gamma, \delta\right)$

\section{REFERENCES}

1. V.Amarendra Babu, T. Anitha and R.Ramya swetha, introduction to difficult to understand topology, diary of cutting aspect inquire about in dynamical and manage frameworks, Vol 9, difficulty 18 , dec 2017,768-780.

2. C.Chang, Fuzzy topological spaces ,J.Math .Anal.Appl., Vol.24, 1968, 182-190.

3. W.L .Gau, D.J.Buehrer,indistinct units, I EEE Trans, frameworks guy and sybernet, Vol. 23, No.20, 1993, 610-614.

4. L. Mariapresenti and i.Arockia Rani, vague summed up alpha close units in topological spaces, worldwide journal of Mathematical Archive, Vol.7, No.8, 2016, 23 - 29.

5. Mary margaret .A,Arockiarani I, vague summed up pre ceaseless mappings, global diary of multidisciplinary research and developement, volume3,problem eight,aug 2016,pg no 60-70.

6. G.F Simmons, creation to topology and modern-day exam , McGRAW-HILL international e book corporation.

7. R.Ramya swetha, V.Amarendra Babu and T. Anitha, indistinct A Generalized Homeomorphism in indistinct Topological areas, global magazine for studies in Engineering application and control (IJREAM), IMC18801, 2018, one hundred-one hundred and five

8. T. Anitha, R.Ramya swetha and V.Amarendra Babu, vague detachment maxims, worldwide gathering on present day tactics In arithmetic And emerging Engineering patterns, Aarupadai Veedu Institute Of technology, ISBN: 978-93-87243-38-five.

9. T. Anitha, V. Amarendra Babu, indistinct LI - requirements on grid thought algebras, magazine of growing trends in Computing and information Sciences, vol.five, No.10, (2014), 788 - 793

10. V.Amarendra Babu,ok.V. Ramarao and indistinct delivered substance gatherings, standard diary Ofapplied arithmetic, Vol.three, No.3, (2015), 50 fifty two.

11. V. Amarendra Babu, Ahmed Allemt,T. Anitha and ok.V.Rama Rao, indistinct topological units additionally, difficult to understand topological brought substance gatherings, Internationa diary of technology and innovative Engineerging and generation, Vol.2, (2017), 1-9.

12. Zadeh L.A, Fuzzy sets, records and manage, Vol.8, 1965, 338-335. 